\title{
"Vencida a veces, nunca prisionera". Georgina Herrera y Belkis Ayón: una poética de la autorrepresentación
}

\author{
Aída Elizabeth Falcón Montes \\ UNIVERSIDAD DE OVIEDO·Aidafalconmontes@yahoo.es
}

Licenciada en Filología Hispánica por la Universidad de Oviedo, donde realizó un Máster y un Doctorado en Género y Diversidad. Ha publicado diversos artículos académicos como "Sonia Rivera Valdés, Entre amigas" (Instituto Asturiano de la Mujer, 2011) o "Género y nación: la representación de la mujer negra en la plástica cubana" (Gacela, $\mathrm{N}^{\circ} 0,2008$ ). Es también autora de obras infantiles como Tía Clara (2010) o Un susurru (2010).

RECIBIDO: 13 DE FEBRERO DE 2013

ACEPTADO: 26 DE MARZO DE 2013

\begin{abstract}
Resumen: El objetivo de este artículo es analizar la Abstract: The goal of this article is to analyze the representación de la mujer negra a través de la obra de la representation of the black woman in the work of the poetisa cubana Georgina Herrera y la grabadora Belkis Cuban poet Georgina Herrera and the engraver Belkin Ayón, y el modo en que el discurso referido a su Ayón, and the way their discourse about their sexualidad, su raza y su género ha contribuido a formar el sexuality, their race, and their genre has contributed imaginario de la identidad nacional. Con el fin de articular towards the formation of a national identity. With the el contexto histórico y social de la población negra en aim of articulating the historical and social context of Cuba, establezco un breve itinerario que parte de mediados Afro-Cubans, I establish a brief itinerary which begins del siglo XX hasta el denominado Periodo Especial en los in the mid $20^{\text {th }}$ century and ends with the so called años 90 del pasado siglo. En una segunda fase, abordo el "Período Especial" in the 1990s. On a second phase, I proceso de autorrepresentación en Herrera y Ayón address the process of self-representation in Herrera mediante el análisis y la posterior comparación de sus and Ayón through the analysis and subsequent producciones literarias y pictóricas respectivamente con el comparison of their literary and pictorial works fin de desvelar las motivaciones que impulsan a ambas a respectively. My objective is to bring to light the elaborar un discurso poético que se sustenta en el legado motivations that lead both women to create a poetic ancestral africano. Como se verá, este estudio ofrece una discourse based on their ancestral African legacy. It visión de la problemática de la mujer negra desde una will become apparent that this study offers a vision of perspectiva feminista, cuyo tratamiento es abordado the Afro-Cuban woman from a feminist perspective. teniendo en cuenta su raza, su clase y su género.

My approach also takes their race, class, and genre into account.
\end{abstract}

Palabras Clave: autorrepresentación, identidad, mujer negra, discurso de resistencia, cuerpo.
Key Words: self-representation, identity, Afro-Cuban woman, resistance discourse, body.

DOI: $10.7203 /$ KAM. 1.2320 
La historia de la población negra en Cuba está marcada por la discriminación racial, el estatus social que desde el régimen colonial ocupó dicho grupo ha contribuido, a lo largo de las diferentes transiciones políticas, a su representación esencialista. De este modo, y a falta de un debate profundo el arte y la literatura han sido los medios idóneos para expresar un conflicto aún latente.

Sin bien la mencionada situación afecta a ambos sexos centraré mi análisis en la mujer negra dado que el discurso referido a su sexualidad, su raza y su género ha contribuido a formar el imaginario de la identidad nacional cubana. La mujer negra ha sido fuente de inspiración de disímiles expresiones artísticas; sin embargo su imagen no ha conseguido escapar de los tópicos que contribuyen a su caracterización física y psicológica. La fisonomía transfigurada de negras y mulatas ha devenido en una especie de discurso icónico que, con el tiempo, convertidas en "personajes", ellas han asumido como propio. A ello ha favorecido también el obligado silencio al que fue sometida, su voz tardó mucho en escucharse.

Dentro de este contexto la irrupción de la mujer afrocubana en el panorama literario y artístico ha supuesto una manera diferente de abordar la situación de este grupo; siendo así, la poetisa Georgina Herrera (1936) y la grabadora Belkis Ayón (1967-1999) se erigen como ejemplos de mujeres dotadas de conciencia propia y aptas para hablar de sí mismas; aunque la distancia generacional entre ambas es considerable y las motivaciones difieren en algunos aspectos, comulgan en la forma de construirse y en la búsqueda de una identidad libre de conceptos ideológicos y programas políticos. A partir de los soportes artísticos que cada una domina, trazan una línea vivencial en la que son sujeto y objeto de su propio discurso narrativo.

Cabe entonces preguntarse ¿Por qué Georgina Herrera y Belkis Ayón sienten la necesidad de autorrepresentarse? ¿Cuál es la herencia histórica y cultural de la que se apropian para iniciar dicho proceso? Las respuestas a estos interrogantes hay que buscarlas en sus biografías y en el corpus de sus obras, pues ambas dialogan con el pasado ancestral africano y es ahí donde descubren una tradición oral de leyendas, ritos religiosos y efemérides en los que el negro es el protagonista.

Por dicha razón, la comparativa poética entre estas dos mujeres nos obliga a establecer un breve itinerario histórico con el fin de entender la problemática racial en general y de la mujer negra en particular puesto que, sus discursos narrativos están inevitablemente interceptados por ese escenario sociohistórico.

\section{El largo camino de la esclavitud a la Revolución}

Durante el siglo XIX, el tabaco y el azúcar fueron los cimientos de la economía cubana, si bien los cambios sociopolíticos y económicos acaecidos dentro y fuera de la isla propiciaron que más tarde el cultivo de la caña primara sobre el del tabaco. En 1791 un 
hecho significativo, como lo fue la Revolución de Haití, hace que este país quede devastado y pierda su primacía como mayor productor de azúcar, coyuntura de la cual se beneficia Cuba y pasa a convertirse en la principal abastecedora mundial.

En Cuba, como en el resto de las islas del Caribe, se establece lo que el historiador Moreno Fraginals define en su libro Cuba/España España/Cuba: historia común, como una economía de plantación: "Una plantación no es una sociedad es un negocio", negocio que según el autor, deriva de una sociedad implantada, creada a partir de una acción empresarial. El personal de este tipo de corporación estaba formado mayoritariamente por negros inmigrados de África, en calidad de esclavos. Este nuevo grupo racial, fue aumentando paulatinamente para satisfacer las necesidades de los terratenientes; aunque todos, hombres y mujeres, procedían del mismo continente, África, quienes llegaron a la isla pertenecían a diferentes etnias y fueron entremezclados de forma intencionada para evitar la cohesión de grupo. Este proceso de "deculturación" (Moreno Fraginals, 2002) al que se les sometió, supuso solo el primer eslabón de una larga cadena de acontecimientos que culminaría con la total integración en una cultura y una nación de la que, a partir de entonces, constituyen un elemento imprescindible.

Es indudable, que la ordenación jerárquica de la Cuba decimonónica respondía a los parámetros de dinero, raza y poder (Moreno Fraginals, 2002: 84-85), siendo los blancos burgueses los ocupantes del vértice de la pirámide, seguidos de los blancos pobres, los mestizos y los negros. La gran cantidad de africanos introducidos a lo largo del siglo XIX fue desequilibrando la balanza con respecto a la población blanca, que se sintió amenazada ante tal avalancha. Los intentos de fomentar la inmigración blanca y eliminar la trata negrera fracasaron por el perjuicio económico que ello suponía para los intereses de la clase dominante. La mano de obra no asalariada e importada de África garantizaba el funcionamiento de las plantaciones y la prosperidad de los hacendados.

Pero lo que en principio fue una solución, el comercio de esclavos negros, comenzó a constituir un creciente problema social; el reflejo de este temor a "lo negro" se apreció en el trato y en el lugar que la sociedad reservó legalmente para este sector de la población, pues es evidente que a cada color de la piel correspondió un estatus diferente.

Los abusos hacia la población negra se intensifican en 1843 cuando el general O’Donnell ocupa el cargo de gobernador de Cuba. Ese año, tras un intento de sublevación en un ingenio de Sabanilla, Matanzas, O’Donnel ordena la ejecución de dieciséis esclavos. En realidad lo que se conoce como La Conspiración de la Escalera ${ }^{l}$ no fue más que un pretexto del gobierno insular para conseguir dos objetivos: debilitar la naciente sociedad

1 Proceso judicial improvisado en el que se utilizó una escalera como instrumento de tortura para obtener la confesión de las víctimas, a pesar de ser un complot racista afectó a intelectuales blancos como Félix Varela, José Antonio Saco y José de la Luz y Caballero. 
pequeño-burguesa de negros y mulatos y apagar la llama abolicionista, independentista y anexionista que se estaba gestando. El Capitán General, con la excusa de localizar el verdadero origen de la revuelta, condenó a pena de muerte a un grupo de mulatos libres, entre los que se encontraba el poeta Plácido² y otras conocidas figuras del ámbito cultural y social de Matanzas. Nunca llegó a probarse la existencia de tal conspiración, si bien la represión contribuyó a frenar las iniciativas políticas de dichos pensadores, además de desestructurar la burguesía negro-mulata.

Los últimos años del siglo XIX en Cuba van a estar marcados por la guerra que se inicia el 10 de octubre de 1868. El adinerado terrateniente Carlos Manuel de Céspedes libera a sus esclavos, tras dar lectura a un manifiesto en su ingenio "La Demajagua". En el comunicado demanda la igualdad de todos los hombres y reclama el derecho a constituirse en una nación independiente. La guerra dura diez años y concluye con el Pacto de Zanjón. Como anuncia dicho pacto, los esclavos consiguen su libertad, las Cortes españolas dictan una serie de medidas a favor de la educación y la creación de servicios sociales para la población negra en Cuba, y pocos años después se produce la plena abolición de la esclavitud. Así, los ex-esclavos tuvieron que adaptarse a las nuevas condiciones, eran libres, pero no poseían medios para sobrevivir en una sociedad que se modernizaba y reclamaba una mano de obra cualificada y, a poder ser, blanca. Las mujeres, los niños y los ancianos fueron los más perjudicados por el hambre y las enfermedades.

La llama independentista no se apagó con el Pacto de Zanjón; Máximo Gómez y los hermanos mulatos Antonio y José Maceo, como cabecillas de la revuelta, no lo permitieron. José Martí, desde el exilio en Estados Unidos, fundó el Partido Revolucionario Cubano. En conjunto organizaron la Guerra de Independencia, que duraría tres años. Juan Gualberto Gómez colaboró también con Martí en la creación del Directorio de las Sociedades de Color, en el que ocupó el cargo de presidente.

En 1898 España pierde Cuba y la isla sólo consigue cambiar de propietario, debido a la intervención de Estados Unidos, cuya injerencia después de la guerra de 1898 destruye los sueños de todos los que habían atesorado la idea de la absoluta soberanía. Con el transcurso del tiempo, la llegada de la República en 1901 se encuentra con una Cuba convertida en un crisol de razas, lo cual se manifiesta en todas sus expresiones culturales. La isla resurge con vocación clasista y racista, aunque irremediablemente mestiza, multicolor, multiétnica. La Guerra de Independencia había unido a los diversos grupos raciales en el campo de batalla. Pero una vez lograda la victoria, cada individuo se reincorporó a su estatus. La pirámide social conservó su estratificación jerárquica, a pesar de que la totalidad de los ciudadanos eran libres. Las promesas que habían hecho Gómez y los liberales de

2 Gabriel de la Concepción Valdés (1809-1844), conocido como Plácido. Representante de la pequeña burguesía de mulatos libres. 
facilitar la integración de la población negra no se cumplieron y los negros continuaron siendo en su mayoría analfabetos y ocupando las profesiones de menor relevancia (Hugh, 2004: 377-383). La influencia norteamericana fomentó la discriminación de los negros, prohibiéndoles la entrada en algunos hoteles, clubes y restaurantes. Las escuelas y colegios privados también les fueron vetados. Este cúmulo de circunstancias preparó el camino para que estallara en 1912 lo que se conoce como la protesta negra, la Guerra del Doce o "guerrita de razas" (Pérez y Luerio, 2009: 354-355) que pronto se extendió por la isla entera. Evaristo Estenoz, líder del Partido Independiente de Color y teniente del Ejercito Libertador, incitó a la revuelta y la organizó. El gobierno actuó de manera contundente: el saldo de muertos se elevó a unos 3.000 negros y mulatos que en su mayoría fueron asesinados, entre ellos se encontraba el propio Estenoz. Al igual que había sucedido a mediados del siglo XIX en La Conspiración de La Escalera, la actuación violenta de las autoridades sirvió de escarmiento a la población negra; sus esperanzas de llegar a cotas del poder político se esfumaron y el efecto inmediato fue la autorreclusión en sus sociedades.

En 1925 Gerardo Machado ocupó la presidencia del gobierno de Cuba. A pesar de sus promesas iniciales su mandato concluyó en 1933 marcado por la corrupción y el descontento popular, que se tradujo en manifestaciones estudiantiles y sindicales. El 3 de septiembre de ese mismo año, el sargento Fulgencio Batista y un grupo de oficiales bajo sus órdenes toman el poder. Batista designa como presidente de la República de Cuba al doctor Ramón Grau San Martín, quien impulsa una serie de medidas sociales tales como el sufragio femenino, la abolición de la Enmienda Platt y la reducción de la jornada laboral. El nuevo gobierno cuenta con el apoyo de los partidos de izquierda de la isla y por ese motivo el gobierno de Estados Unidos manifestó su descontento con los cambios que pretendía Grau y amenazó con interrumpir las importaciones procedentes de Cuba. Por su parte Batista, para satisfacer las exigencias de Washington, frenó las transformaciones sociales que estaba experimentando el país y en 1940 asumió la presidencia de Cuba. Su mandato arrastró a la población al paro y a la pobreza de manera que la respuesta no se hizo esperar: perdió las elecciones de 1944. Ocho años más tarde, coincidiendo con los comicios de 1952, organizó al ejército y dio un golpe de estado el 10 de marzo contra el gobierno de Carlos Prío Socarrás. Batista, mulato y de origen humilde, se convirtió en un dictador populista. Los negros le dieron su apoyo confiando en sus propuestas, pero la forma en que actuó y desarrolló su legislatura vino a demostrar que sus promesas de igualdad para todos eran sólo una estrategia política y una manipulación del conflicto racial cubano. La mayoría de la población afrocubana era analfabeta, y sólo muy pocos de ellos tuvieron la oportunidad de prepararse como obreros especializados, técnicos o universitarios, lo que dio pie a la aparición de una clase media de color, un grupo poblacional que continuaba reuniéndose en sus sociedades, clubes y salones. Las mujeres negras se dedicaban 
fundamentalmente al servicio doméstico, excepto algunas que alcanzaron la condición de maestras, mientras que para aspirar al empleo de dependienta en una tienda de lujo debían estar avaladas por una titulación de nivel superior al que se exigía a las mujeres de raza blanca.

La etapa final de la dictadura batistiana se caracterizaron por la prevaricación política, la represión y el terror. Fidel Castro, que ya en 1947 era un reconocido líder estudiantil, preparó el camino para el triunfo de la Revolución; después de fracasar en sus primeros intentos, en 1953, con el ataque al Cuartel Moncada, retoma la lucha. Desde la Sierra Maestra, en la zona oriental de la isla, organiza junto a su hermano Raúl Castro, el Che Guevara, Camilo Cienfuegos y otros combatientes destacados, la ofensiva final cuyo triunfo en 1959 gesta un cambio radical. Cuba emprende un proyecto socialista, integrador y basado en la unidad nacional; las leyes de reforma agraria, urbana, educativa, de salud pública y tributaria son la prioridad del gobierno. Sin embargo, la reforma más significativa es la que eliminó las desigualdades sociales institucionales. La población negra (en su mayoría analfabeta) tiene la oportunidad de incorporarse a la nueva sociedad en igualdad de condiciones. El añorado sueño de este sector de la población, que se había postergado tantas veces, se convierte por fin en una realidad. El conjunto de medidas promulgadas por la directiva revolucionaria facilitaba la equidad racial y eliminaba las barreras que antaño obligaba a reunirse en espacios sólo para negros. Con todo, en el transcurso del proceso revolucionario los negros ocuparon muy pocos cargos dentro del poder gubernamental, de forma que su invisibilidad, en este sentido, se reprodujo en el nuevo contexto histórico.

En septiembre de 1990 el gobierno de Cuba declaró el inicio del llamado Período Especial. La grave crisis que supuso la caída mundial del campo socialista y el recrudecimiento del bloqueo por parte de Estados Unidos, se tradujo en un nuevo orden económico en el que la bipolaridad desapareció. A partir de ese momento, la entrada de otras economías de mercado fue un hecho y la situación cubana se ve afectada. Reaparecen las diferencias sociales, el mercado negro prolifera como un medio de obtener los recursos que antes estaban garantizados, y retorna la prostitución que había sido erradicada. El éxodo hacia Estados Unidos y Europa es la opción anhelada por muchos cubanos.

\section{Entre la resistencia y la desobediencia}

Con todo lo anterior en mente, podemos comprender la razón por la cual Georgina Herrera comienza el camino de la autorrepresentación casi de manera innata cuando es una niña. Su nacimiento en Jovellanos, un pueblo de la provincia de Matanzas "eminentemente de personas negras" (Rubiera Castillo y Herrera, 2005: 50), puede interpretarse, desde una perspectiva literaria, como una predestinación pues, según nos refiere Herrera en su autobiografía Golpeando la memoria, allí tuvo lugar una de las sublevaciones más importantes de la zona en la que murieron un número elevado de esclavos. Este dato nos 
informa del entorno en el que vivirá Georgina Herrera hasta los veinte años y que se constituirá no solo en la metáfora de su posición rebelde y trasgresora ante el mundo sino también en una prolongación de su identidad por eso, desde las primeras páginas de su autobiografía deja patente qué significa ser negro y pobre en la Republica Neocolonial en la que transcurre su infancia.

Allí comencé, también, a apreciar la significación de ser pobre y sobre todo negra, porque después de tomar conciencia de mi condición de clase cuando tenía que asistir a la escuela con los zapatos rotos, vino la de mi identidad de raza (Rubiera Castillo y Herrera, 2005: 25).

Ante las carencias afectivas, la pobreza y la discriminación racial se rebela rechazando y agrediendo su cuerpo que, en cierta manera, se convierte en el soporte textual primigenio a través del cual habla del dolor y la frustración.

En aquellos tiempos la discriminación era tan fuerte, que hubo un momento en el que no quería ser negra, no me sentía bien siendo negra. Quería ser blanca, y para lograrlo, a escondidas de mi mamá, me planché el pelo y me ¡me quemé! Con una palito de tender la ropa me prendí la nariz para ver si se me estiraba y ¡pasé tremendo dolor! Uno de los castigos y una de las penitencias más deliciosas que recuerdo (Rubiera Castillo y Herrera, 2005: 25).

Herrera impugna su corporeidad para que, aún sin saberlo, encaje en la retórica nacional del momento y así librarse de un estigma de sumisión y rechazo, pero este episodio, supuestamente pueril, no la ayuda a construir una gramática visual del negro porque no repercute más allá de su intimidad. Quienes gobernaban en aquel entonces y los sucesivos estadistas que tuvo Cuba hasta el triunfo de la Revolución, trataron por todos los medios de controlar a esa clase "inferior", destinando lugares concretos, atribuyéndoles maneras de expresarse, fabricando Otro enemigo con el objetivo de diseñar una nación monocolor. Parafraseando a Foucault (2006: 134-140) podríamos decir que una de las formas principales de conciencia de clase fue la afirmación del cuerpo; la burguesía blanca convirtió el color de la piel en un signo de superioridad, relacionado con lo positivo, con el modelo que se debía de seguir en todos los aspectos. Por eso, no es de extrañar que Herrera intentara asemejarse a ese otro "cuerpo social" privilegiado y con ello dramatizar un conflicto, que con otras particularidades, todavía persiste.

En este mismo sentido Gabriella Buzzatti y Anna Salvo en su libro El cuerpo-palabra de las mujeres apuntan (2001:33):

[...] el uso del cuerpo en lugar de la palabra, el hecho de que represente una reserva grandiosa y, al mismo tiempo, «mísera» - en el sentido en que Freud hace referencia a este término para connotar el síntoma-, reserva para 
accidentes e incidentes donde se aglutinan sentimientos remotos, trasciende con mucho el modo común de entender el campo psicosomático.

La literatura viene a ocupar, posteriormente, el lugar de ese cuerpo herido, delator, "campo psicosomático", y le permite sobrellevar su situación familiar, canalizar la ira, en definitiva, crear otros mundos posibles alentada por los relatos de las mujeres negras de la familia; se advierte en ella un empeño claro de ser actante de su propio discurso frente a un nadie privado de derechos en el ámbito doméstico y público.

Mi papá y mi mamá no se daban cuenta de eso, de que yo ¡no era nadie! Por eso sentía mucha necesidad de expresarme, de comunicarme con los demás. Creo que ese enfrentamiento con mi condición de segunda hija y la postura que adopté ante la vida, a pesar de mi corta edad, fueron las razones de que comenzara a escribir poemas (Rubiera Castillo y Herrera, 2005: 23).

Herrera articula su subjetividad paso a paso, en consonancia con la capacidad de observación que hubo de desarrollar como defensa psicológica ante el entorno hostil en el que creció. El estilo sencillo de su autobiografía recuerda los relatos de la tradición oral y despliega un puente comunicativo y dialógico con el lector. El relato individual de la autora adquiere, sin proponérselo, una dimensión histórica y política porque establece un cuidadoso paralelismo cronológico entre las representaciones de la mujer negra y las condiciones sociales impuestas por los diferentes gobiernos instituidos en la isla.

Los acontecimientos históricos, antes mencionados, forman parte de los reflejos contextuales que pueden rastrearse en la autobiografía y la poesía de la escritora, lo cual señala su voluntad de incorporar el pasado en el presente y hacer el largo viaje desde la invisibilidad apoyada en la tradición oral de la que es deudora.

Mi abuelo se incorporó a la Guerra del 95 cuando las tropas de Maceo pasaron por Coliseo [...] Hablaba con orgullo del valor de los mambises, y por la suerte que tuvo de que nunca lo hirieran. En ninguna de sus historias hizo referencia al racismo, no lo entendía, no estaba en sus valoraciones, pero a través de sus cuentos, más tarde me percaté del cierto rechazo que los campesinos de la zona central del país hacían a las tropas de Maceo (Rubiera Castillo y Herrera, 2005: $48)$.

Georgina Herrera puede datar y nombrar la segregación racial de la que fueron víctimas los negros durante varias décadas gracias al testimonio de las muchachas negras de su pueblo que trabajaban en La Habana como empleadas del hogar, a las dificultades por las que pasó su hermana para encontrar una plaza fija como maestra a causa del color de la piel y a su propias circunstancias vitales:

Casi finalizado el año 1958, ya había terminado mis estudios de Secretariado, razón por la que comencé a solicitar trabajo a través de anuncios clasificados de 
los periódicos: "muchacha negra, mecanógrafa, con conocimientos de taquigrafía, se ofrece para atender un teléfono o para atender una oficina". Parece que lo de "muchacha negra” desempeñó su papel, porque jamás me contestaron (Rubiera Castillo y Herrera, 2005: 93).

Cuando en 1956 se traslada a la capital comienza una nueva etapa no exenta de sacrificios; sin embargo, recibirá un gran estímulo con la publicación en 1962 por la Editorial El Puente ${ }^{3}$ de su primer libro titulado $G H$.

Aunque utilizar las iniciales de su nombre para titular el poemario no fue una idea de la autora, será a partir de ese momento un rasgo definitorio de su corpus poético: Gentes y cosas (1974), Granos de sol y luna (1978), Grande es el tiempo (1989), Gustadas sensaciones (1996), Gritos (2004) y Gatos y liebres o libro de las conciliaciones (2009). Las iniciales de Georgina Herrera más que una constatación de autoría son una rúbrica sobre su nombre propio, un cuño imborrable y de enunciación de un yo pleno y orgulloso. Moustapha Safouan, en su recopilación de los seminarios de Lacan, refiere las palabras del mismo en relación con la identificación del sujeto y el nombre propio, que viene a corroborar el simbolismo que para Herrera entraña este hecho.

Teniendo en cuenta la negatividad del signo, concluye Lacan, parece que el nombre propio, en tanto que identifica el arraigamiento del sujeto, está más ligado que otro, no a la fonematización o a la estructura del lenguaje, sino a lo que ya en el lenguaje está listo para recibir esa información del rasgo. Hasta hoy el nombre propio sigue llevando la huella: no se traduce de una lengua a otra (Safouan, 2003: 189).

El nombre encierra un número importante de significaciones y su eliminación intencionada borra toda marca identitaria del sujeto, tal y como sucedió bajo el régimen esclavista donde los colonos le asignaban nombres cristianos a sus esclavos. Por tanto, este acto de Herrera puede leerse igualmente como una parábola de la emancipación en la que ella se rescata; en palabras del sociólogo jamaicano Orlando Patterson, de una "muerte social" (1991: 36). Dicha definición alude de manera global a las condiciones degradantes en las que los esclavos vivieron y que los despojó de cualquier expresión cultural y social autentica que no estuviese vinculada a las relaciones de poder amo/esclavo. "La muerte social era como la muerte física: una vez muerto se permanecía muerto" (Patterson, 1991: $40)$.

Re-cuperar y re-parar son términos afines que se conjugan en Herrera y que están presentes en su obra y en la forma de proceder según sus convicciones; una vez

3 Proyecto editorial que surgió en 1961 formado por intelectuales jóvenes y que finalizó en 1965 rodeado de polémica y acusado de no ajustarse a los valores que proponía la naciente Revolución. Figuras destacadas como Nancy Morejón y Miguel Barnet publicaron aquí sus primeros textos. 
incorporado el pasado ancestral se enfrenta nuevamente al espejo; pero no para impugnar su corporeidad como hiciera de niña, sino para apoderarse de esa mujer negra que frente a la contemplación de una máscara africana, se reconoce y escribe el poema "Primera vez ante el espejo", "me hice consciente plenamente de mi identidad racial" (Rubiera Castillo y Herrera, 2005: 82). La máscara cumple para Herrera la función del espejo y "la imagen especular es asumida jubilosamente" (Lacan, 2003: 87). Aunque este "reflejo" no puede imitar sus movimientos y ofrece solo un fragmento de su cuerpo, metafóricamente, el esbozo africano se muestra como una réplica coordinada de la escritora. A pesar de que el encuentro más genuino con su cuerpo se produce en la edad adulta y a través de una imagen escultórica, no siente la necesidad de apedrearlo es ella ahora la que espía su cuerpo, lo expone y exige que se acepte tal como es. Georgina Herrera se autorrepresenta ligada física y espiritualmente a su genealogía femenina africana. Nos ofrece un rostro negro, de "espaciosa boca", "ojos / tremendos" (Rubiera Castillo y Herrera, 2005: 82). El yo lírico se manifiesta mediante un recurso expresivo como es la pregunta, " ${ }_{\mathrm{C}}$ Dice alguien que no es / mi rostro este que veo, / que no soy yo ante el espejo / más limpio reconociéndome?", (2005: 82) a la que sigue una larga respuesta descriptiva y emocionada en torno al rostro que huele, mira, besa con intensidad, y de esta manera concluir el recorrido con la aserción de un "Soy yo" objetivado y recién descubierto. Su capacidad de aprehender el mundo y su rebeldía la liberan de complejos, prejuicios y de la mirada deformada del Otro, por esta razón, al ver las máscaras africanas ve una alteridad de sí misma, y asume su cuerpo con el largo itinerario de experiencias, subjetividades y por tanto como realidad social susceptible de ser representada íntegramente, lejos de cualquier percepción reductora y básica. Georgina es su yo alejada del discurso de odio ${ }^{4}$ desde el cual la construyeron como mujer negra y que ella ha transformado en un discurso oculto y de resistencia porque tal y como expresa James C. Scott (2003: 33):

Un individuo que es ofendido puede elaborar una fantasía personal de venganza y enfrentamiento, pero cuando el insulto no es sino una variante de las ofensas que sufre sistemáticamente toda una raza, una clase o una capa social, entonces la fantasía se puede convertir en un producto cultural colectivo.

La libertad poética de Georgina Herrera, le ha permitido edificar esa fantasía que menciona Scott no tanto como venganza sino como afirmación social; ella hace su propia revolución interna de este modo, sitúa a sus ancestros y se reserva un espacio en el que tiene voz, protesta, reclama y propone un lugar poético de desobediencia. En Herrera lo social y lo íntimo se entremezclan, lo público invade lo privado en tanto la afecta a ella como mujer, negra y pobre; y lo privado lo público, porque su vida es el ejemplo y la secuela del individuo marginado.

4 Teoría enunciada por Judith Butler, en su libro Lenguaje, poder e identidad(Síntesis, 2004). 


\section{Sikán o la mujer trascendida}

Belkis Ayón, nacida en La Habana, se incorpora profesionalmente al ámbito del grabado cubano en los años 90 del pasado siglo y lo hace en el momento en que la isla atraviesa por una grave crisis económica que despierta reivindicaciones y debates que se habían aplazado, muchos escritores y artistas afrocubanos interpelan a la historia con sus obras; se remiten a sus orígenes y dialogan con la estética que los había representado. Pero Ayón, va más allá, su mundo poético no se adscribe a ninguna causa colectiva como bien manifestó en muchas

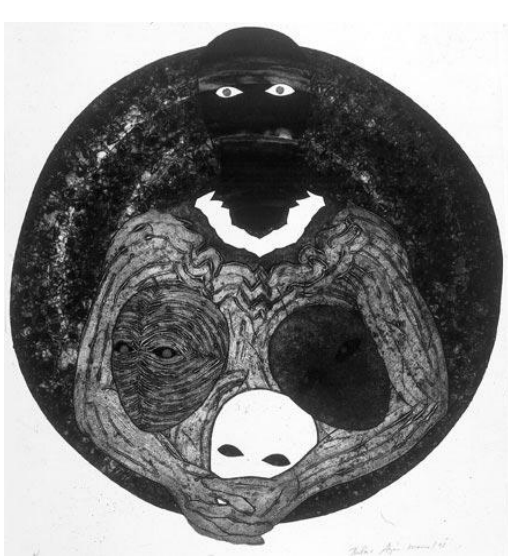

Intolerancia, Belkis Ayón, 1998. ocasiones en la que explicaba que su obra no podía interpretarse desde una perspectiva racial, ni feminista. Al igual que Georgina Herrera ella es el eje de su producción artística y su mirada se dirige a África en busca de otro lenguaje para representarse, al que llega tras una rigurosa labor investigativa sobre la sociedad secreta Abakuá o Ñañiga, cuyos orígenes se remontan al siglo XIX.

Dicha sociedad es eminentemente masculina y las mujeres no son admitidas en ella, veto que encuentra su explicación en la leyenda de Sikán: Una mujer de nombre Sikán, fue al río Oldar a coger agua en una tinaja en la cual se introdujo imprevistamente el pez Tanze, representante de Abisi. Quien capturara al pez y su secreto, la voz, tendría la tribu más próspera. Sikán pagó con su muerte el descubrimiento del sagrado enigma. Por eso, en el proceso de ceremonias de los ñáñigos, Sikán aparece representada mediante un chivo y con su sacrificio se reconstruye la leyenda.

Este es el trasfondo etnocultural sobre el que se asienta la obra de Belkis Ayón que se apodera de

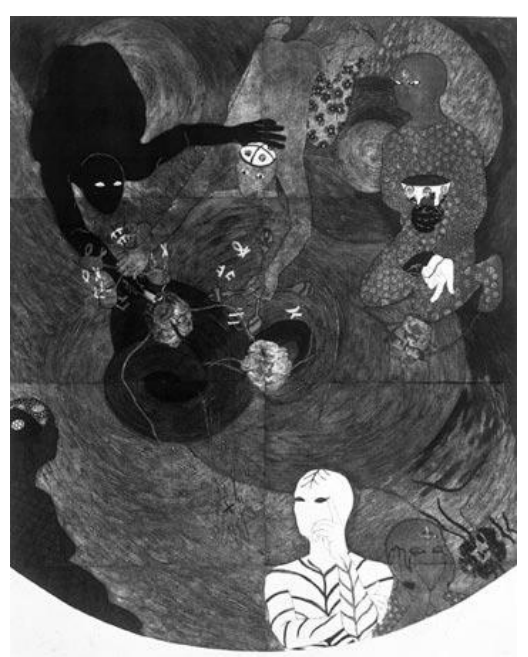

Desobediencia, Belkis Ayón, 1998. los códigos cifrados de los ñáñigos y de su mito fundacional para transgredirlos no como un acto de intrusismo, sino como un ejercicio de resemantización del propio yo que le permite hablar de Intolerancia (1998), Desobediencia (1998), Acoso (1998) y especialmente de Sikán (1991), esa mujer que en manos de Ayón deja de ser víctima para adquirir la representación gráfica que los ñáñigos como sociedad religiosa masculina le niegan. Otro 
aspecto relevante de las fuentes de las que se sirve es el carácter marginal atribuido a este grupo en la isla, propiciado por el desconocimiento de las costumbres y comportamientos de esta sociedad y por extensión de todo un sector poblacional. Lázara Menéndez ahonda en este aspecto y explica:

En el entorno sociocultural cubano, la fuerte tradición de descredito relativa al ñañiguismo benefició un estrategia elusiva sobre la cuestión abakuá, empeñada en convertir a esta porción de la población nacional en un depositario de remanentes que persisten de un pasado ajeno y /o marginal (Ayón, 2010: 63).

Una vez más la imagen especular, como ocurre en Herrera, no se encuentra en la superficie pulida que constituye el espejo porque el reflejo aparece en esos pedazos de intrahistoria y de tradición oral. La figura de Sikán se funde con la de Ayón como ella misma afirmaba [...] la imagen de Sikan es evidente en todas estas obras porque ella, como yo, vivió y vive a través de mí en desasosiego, buscando insistentemente una manera de salir (Ayón, 2010: 26).

No cabe duda de que el cuerpo es el soporte donde confluyen todas las experiencias vitales y la pieza primordial en la construcción de la subjetividad; Ayón rompe con las leyes de la reflexión para manipular su imagen y dotarla de un contenido íntimo: "quizás mi obra sea eso: son cosas que tengo dentro y que echo para afuera porque son cargas con las que no se puede vivir ni se pueden arrastrar" (Ayón, 2010: 22).

Sus personajes son seres asexuados, enigmáticos, desprovistos de la boca/voz/palabra pero que aglutinan todas las funciones sensoriales en una mirada que grita y observa. La rehabilitación identitaria que Ayón promueve legitima su discurso poético y rescata de la invisibilidad intencionada a la

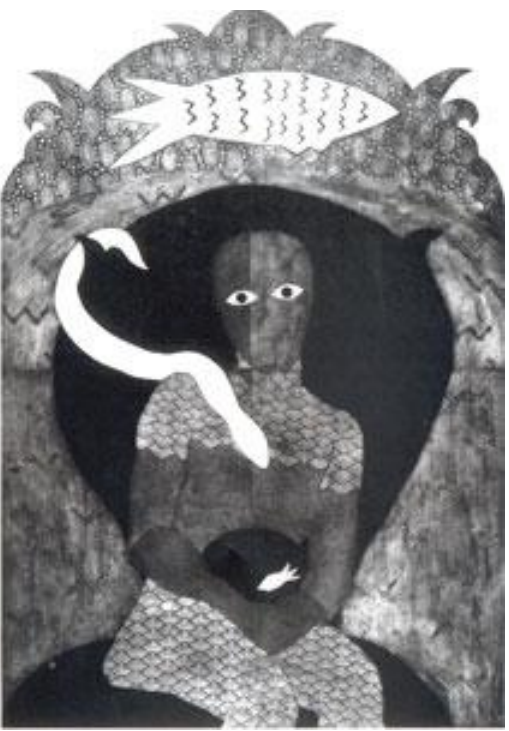

Sikán, Belkis Ayón, 1998. mencionada sociedad ñáñiga.

Inevitablemente, la obra de esta joven grabadora trasciende lo individual y no puede desvincularse del elemento sociohistórico y de condicionamientos tales como la raza, el género y la clase. Ella corona con su iconografía a esas mujeres negras que no han podido librarse de un estereotipo en el que se les destrona porque sus rasgos físicos se hiperbolizan para ser objeto de burla y sus costumbres religiosas son calificadas de superstición. 
Coronación y destronamiento, carnavalización del sujeto a la manera que lo entiende Mijail Bajtin ${ }^{5}$. En este sentido Sandra Ramos refiere lo siguiente:

$\mathrm{Al}$ adentrarse en el estudio desde la perspectiva de una mujer negra en el mundo contemporáneo y específicamente en Cuba, Belkis encontró quizá inconscientemente un alter ego ancestral, alguien también torturado por su inadaptación al contexto, por su conciencia de culpa, por su exceso de responsabilidad, por la presión del medio hacia el individuo, presión sutil de género, de raza, de educación, de familia.

Sikán es Belkis con sus ojos grandes que nos mirarán siempre recordando esa belleza frágil que tuvimos y no supimos conservar. Su obra es, algo vivo y humano. Su muerte, una responsabilidad compartida (Ayón, 2010: 83).

Belkis Ayón puso fin a su vida a los 32 años de edad dejando tras de sí una obra coherente y múltiple en significados.

\section{Reflexión final}

El patrimonio cultural que Herrera y Ayón comparten acorta la distancia generacional que las separa y las congrega en un área común de reparación psicosocial. La recreación de un espacio conocido solamente a través de la tradición oral por una parte y del estudio consciente por otro se instituyen como un único discurso antagónico y de resistencia para abrirse camino en una realidad social compleja.

El cuerpo aparece junto a los poemas de Herrera y las colografías de Ayón como sustrato transmisor de una ideología, de una cultura, de una versión de la historia aún por contar. Ambas se autorrepresentan desnudando su intimidad, exponiendo su visión del mundo después de examinarse frente al espejo. A Georgina el trayecto vital le permite definirse como mujer negra y feminista, Belkis en cambio huye de cualquier definición y a pesar de que trunca su recorrido existencial con un aparente silencio evidencia la disconformidad con el contexto en el que le tocó crear.

La imagen que proyectan Georgina Herrera y Belkis Ayón se libera de las pautas arquetípicas que encorsetan a la mujer negra y que perviven en el ideario actual de la sociedad cubana. Ellas se hicieron visibles y reconstruyeron su identidad alejada de cualquier concepción maniqueísta, estableciendo un lugar intermedio, un nuevo condicionante en el significado de lo nacional para abrir nuevas puertas en la hermenéutica fundacional de lo cubano en la que el negro es un elemento imprescindible.

Lo indefinido, lo encapsulado, lo diferente, cambia de estatus para así controlar un desafío que se impone ante el desconcierto. Quizás por eso, precisamente porque rompen

5 Mijail Bajtin desarrolla su teoría sobre la carnavalización del sujeto en su libro: La cultura popular en la Edad Media y en el Renacimiento: el contexto de François Rabelais, publicado en 1965. 
Aída Elizabeth Falcón Montes

esquemas, se empieza a desconfiar del poeta, del mendigo, del inmigrante y de tantos otros grupos sociales; se delata una vez más la tendencia del poder instituido a controlar y definir a fin de perpetuarse en el tiempo. 


\section{Bibliografía citada}

Ayón, Katia (eda.) (2010). Nikame: Belkis Ayón. Madrid: Turner.

Bajtín, Mijail (2005). La cultura popular en la Edad Media y el Renacimiento: el contexto de Francois Rabelais. Madrid: Alianza.

Butler, Judith (2004). Lenguaje, poder e identidad. Madrid: Síntesis.

Buzzatti, Gabriella y Salvo, Anna (2001). El cuerpo-palabra de las mujeres. Madrid: Cátedra.

Foucault, Michael (2006). Historia de la sexualidad 1: la voluntad de saber. Madrid: Siglo.

Hugh, Thomas (2004). Cuba la lucha por la libertad. Barcelona: Debate.

Lacan, Jacques (2003). "El estadio del espejo como formador de la función del yo tal como se nos revela en la experiencia psicoanalítica". Escritos 1. México D.F.: Siglo XXI: 86-94.

Moreno Fraginals, Manuel (2002). Cuba/España, España/Cuba: historia común. Barcelona: Crítica.

Patterson, Orlando (1991). La libertad en la construcción de la cultura occidental. Chile: Editorial Andrés Bello.

Pérez, Esther y Luerio, Marcel (2009). Raza y racismo. La Habana: Editorial Caminos.

Rubiera Castillo, Daisy y Herrera Georgina (2005). Golpeando la memoria: testimonio de una poeta cubana afrodescendiente. La Habana: Ediciones Unión.

Safouan, Moustapha (2003). Los seminarios de Jacques Lacan 1953-1963. Barcelona: Paidós.

Scott, James C (2003). Los dominados y el arte de la resistencia. Tafalla: Ediciones Txalaparta. 